\section{Registration is now open!}

Registration for the British Dental Conference and Dentistry Show 2020 is officially open!

Now you can secure your place at the event to make sure you don't miss out on the extensive education and networking opportunities available. A world-class speaker line-up has been accrued, with industry-leading professionals sharing their colossal collective experience and expertise.

There will also be an extensive trade floor with dental manufacturers and suppliers demonstrating their latest innovations. Whether you're looking for digital technologies, restorative materials, software programmes or training courses, there will be something for you.

$10,000+$ visitors

$400+$ exhibitors

$200+$ speakers

$100+$ hours of education content

Don't miss out and register for free online today!

The British Dental Conference and Dentistry Show 2020 - 15 and 16 May -Birmingham NEC, co-located with DTS. For all the latest information, visit www.thedentistryshow.co.uk, call 02073485270 or email dentistry@closerstillmedia.com.

\section{Keeping on top of infection control}

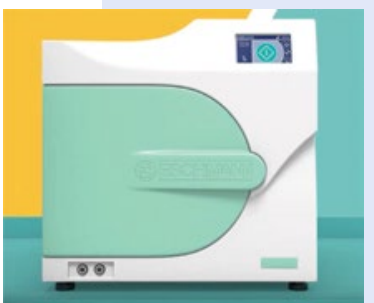

With so many illnesses making a resurgence, infection control is now, more than ever, a top priority in dental practices.

Ensure that you choose an affordable, reliable autoclave such as one of the Little Sister range from Eschmann.

Whether you prefer a vacuum or non-vacuum model, Eschmann has an autoclave that will suit your individual needs and aid compliance every step of the way. Furthermore, each model has numerous features designed to help make infection control even easier, including rapid cycle times and active drying.

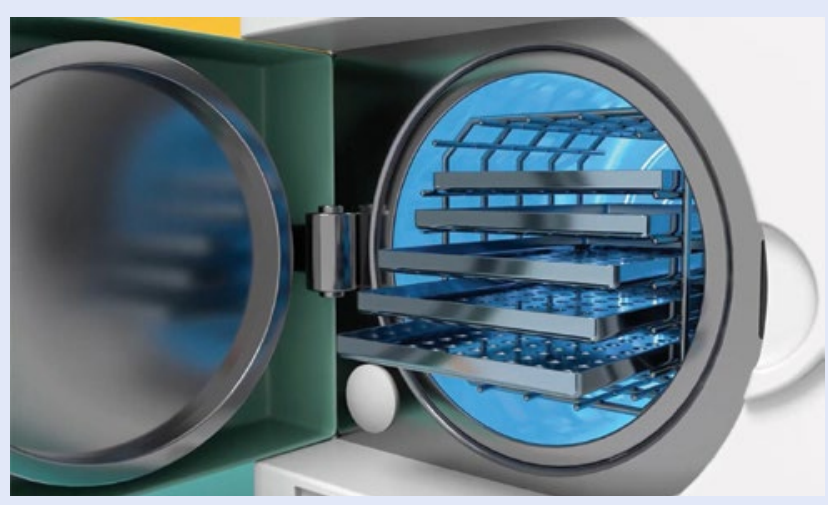

So, if you want to ensure that your infection control is easy, efficient and incredibly effective, contact the team at Eschmann and find a Little Sister that suits you today.

For more information on the highly effective and affordable range of decontamination equipment and products from Eschmann, visit www.eschmann.co.uk or call 01903875787.

\section{A complete range of endodontic solutions}

To successfully dissolve vital and necrotic tissue, eradicate bacteria and other microorganisms, remove the smear layer and lubricate the canal system, try CanalPro endodontic solutions from COLTENE.

All products have been designed and manufactured to minimise the time and effort spent on irrigation and offer a simple yet effective solution to disinfect canals to a high standard for optimal outcomes.

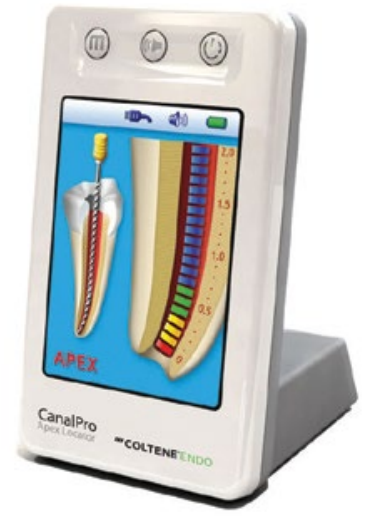

For the successful irrigation and debridement of root canals during and after instrumentation, there's the CanalPro $\mathrm{NaOCI}$, which is available in a $3 \%$ and $6 \%$ formula. COLTENE also offers CanalPro EDTA $17 \%$ to remove the smear layer and dentine mud and open dentine tubules, and CanalPro CHX 2\% for additional rinsing and for use during revisions.

No single solution exists that can effectively and safely achieve complete debridement, but with COLTENE's complete range of CanalPro endodontic solutions irrigation can be successfully achieved.

To find out more visit www.coltene.com, email info.uk@ coltene.com or call 01444235486.

\section{Faced with a complex endodontic case?}

Are you ever faced with complex endodontic cases where you're unsure how to proceed?

Why not refer to EndoCare?

EndoCare's team are dedicated to keeping up to date with all of the latest treatments in endodontics, meaning that they always do their best to save the tooth in every case. This way, EndoCare have managed to save thousands of teeth that would otherwise have needed extraction!

EndoCare also gives patients the option to listen to music or watch movies during treatment. This is perfect for anxious patients or those who have dental phobias.

So, if you have a case where you're unsure how to proceed or an anxious patient who needs special attention, be sure to refer to EndoCare today.

For further information call EndoCare on 02072240999 or visit www.endocare.co.uk. 